\title{
To my Friends and Colleagues: Thoughts from Brazil
}

Let's stop a moment and examine what it is that we (educators and researchers) do together. Research is planned, designed, and carried out within the boundaries of a research paradigm. A proposal is presented to an ethics committee and defended before a group of colleagues to obtain consent, approval, support, and finally to earn a master's degree or a doctorate. We know that this is "how things work" at the university. As a Master's of Education student in the field of TESOL, I can appreciate that these structures exist to help us organize and make sense of knowledge in the most productive and ethical way possible to us.

But I have always struggled with the idea that most research in the TESOL field is still positivist, a paradigm that seeks an objective and factual representation of results. In a field such as ours, where we work with people and language, I continue to have difficulty seeing how the individual personalities and experiences of the people involved in the research don't get in the way of objectivity. Educational research and practice is unique because we are human, more uncountable than countable (as nouns go). Having lived with each other in the same hallways, lounges, office spaces, meeting rooms, and classrooms, we can rest assured that researchers, teachers, and students are people, not subjects. And we thus leave fingerprints everywhere at the research scene and on the research results.

To resolve this dilemma, I designed a master's thesis proposal on pictures in ESL texts under the qualitative research paradigm of critical pedagogy. Founded on the work of Brazilian Paulo Freire, this paradigm encourages us to consider with / for our students: how the existing power structures came to be as they are, whose interests are served by these structures, and what can be done to change the situation. I chose this paradigm because I was drawn to the notion that teachers and researchers could help individual people to empower themselves and improve the material circumstances of their lives. Then again, maybe I was just plain egoistical and naive.

I had not paid close enough attention to the fact that empowerment needs to come from within a person in a social class of a particular culture. And if the people gaining the most or the least from the existing power structures don't want to confront the realities-because to do so would be emotionally painful or would require giving up a comfortable way of life--it may not be our place as researchers (in my case a white, educated, middle-class foreign 
researcher) and outsiders to challenge them. As you will see in the second piece, "Buses," the fact that I initially had difficulty taking a bus in São Paulo hardly qualifies me to empower the very Brazilians who take the bus everyday.

But wait! I'm not suggesting that we avoid qualitative paradigms either. Rather, I am suggesting that it is the limitations of research paradigms that can and will raise the most interesting questions in research, questions found in my letter to the two professors whose insights have challenged my intellect and understanding of our field, Drs. Sandra Kouritzin and Yatta Kanu.

I also think we need to dust our research for our fingerprints by identifying who we are and what moves us to do the research that we do. The last piece, "Gringa in the Borderland," tells you about my language learning and acculturation experiences as person choosing to do her research in Brazil, not for all of Paulo Freire's brilliant words, but because she fell in love with a Brazilian in Canada, and her work has followed her heart to Brazil.

\section{Dear Sandie and Yatta,}

A moment of honesty. I thought I was ready for this. But I had no idea. I thought I would be tough. Until I got here.

I have read about culture shock. In fact, I've read a lot about culture shock before I left and since I got here. I can accept that there is a certain period of adjustment. The phases of excitement, fear, depression, and settling in have come and gone. I've got past the rough stages of living in a different country: I can get around and I am beginning to love some things about Brazilian culture. I've read several books on the history of Brazil and ordered more from Amazon.com. Moreover, I love Fabricio, everything with us is more than wonderful, but I need to write.

But what urges me to write is the same thing that gets me physically and emotionally depressed at times. Although I feel like I finally have my head above water as far as the culture shock goes (I'm sure you've noticed by now that that "settling-in period" in my proposal timeline has doubled), what I feel myself desperately wanting to write about is the same thing that most people here with any money at all try to hide from: the poverty, the pollution, the traffic, the noise, the smell of the river that runs through São Paulo, and people who are just surviving. But to write is to recognize that this exists. I want to "look" with my writing but it is painful. I feel as though I am being educated through my heart.

Paulo Freire's ideas are a paradox. I feel this more and more. To educate people and give them a voice in the written word may be hope, but not without consequences. I' $m$ finding it hard to look reality here straight in the face as a (relatively) well-off white foreign woman. Imagine what 
recently educated people in the favelas (slums) with mouths to feed must "see" when they "realize" what they are up against. When people have money, they take every opportunity to hide in nice cars with the windows rolled up in summer, avoid walking on the streets with the popular class, and shop only in fancy malls with expensive beautiful things modeled on Western lifestyles and fashion.

I realize that I am somewhat off the subject of pictures in ESL texts, the topic of my thesis. Maybe at this point you are wondering what I am doing down here. But I think about some of my discussions with both of you almost every day now.

I work for the best language school in São Paulo. The prices are outrageous and my clients are wealthy, important business figures in their respective markets. But the more I talk to them, the more I realize that they spend their lives hiding behind walls that they themselves seek out: walls topped with broken glass or barbed wire with guards. I also have to request a pass card and go through two security barriers to get to their offices. Or walls that they themselves construct: they relax at beach homes, mountain retreats, or fancy clubs away from the people and the "reality" that makes them "uncomfortable" or they go to restaurants to be with "beautiful people." The point is that they see what they want to see. I knew that after the first month of working with them. They hire the poor as housekeepers and consider that a contribution to society's ills. My own boss at the language institute describes the districts of the city as either "civilized or uncivilized." Imagine.

And I am ashamed to admit that I can understand why they do it, all the while feeling angry about even feeling that way. I mean I have so much privilege as a foreigner. There are whole magazines devoted to how Latin American women can transform their bodies with plastic surgery to look more like a white "California girls." Yatta, you told me that was the case and you are right. The cultural imperialism is also molding and shaping the bodies of women here. This greatly upsets me, but if I try to raise the issue with any of my students they will surely wonder, "Who is she to complain?" I am tripping on paradoxes down here!

\section{Buses}

Let's do a simulation exercise, shall we? Put Canadian (you) at bus stop in São Paulo. OK, now ... Wait. (There is no scheduled time, so you just need to wait, OK?) Keep waiting. No, put your book away. You need to pay attention because the bus comes fast and furious. Trust me. Look here it comes. 
WhoOoM!

And there it went.

I made the same mistake my first time. It's OK. You see, you've gotta wave your hand in the air so the driver sees you want him to stop. Otherwise, he'll just keep on driving. Don't look so frustrated. Three buses drove by before I figured it out. First rule of being a foreigner is "When in a state of uncertainty, watch what other people do" (and hopefully another foreigner isn't watching you).

Look, another bus is coming.

OK, less enthusiasm. You are not signaling a rescue mission on Survivor. Raise a pointed finger in the direction of heaven (because that's where you may go after the ride) ... what? Nothing. I said, "Raise a pointed finger in the air and it will stop." Good.

\section{SCREEEEEEEEEECH.}

Don't just stand there! Get on! The bus doesn't wait for daydreamers and ogling tourists.

REEEEEEEEEEEEEEEEEEE ... (bus shifting gears. Work with the sound effects available, OK?)

Wait a minute. Don't offer the driver money. He just drives. That's enough. See that guy sitting at the small desk up in the middle of the bus? You gotta pay him. Then he lets you pass through the gate to the back of the bus where the doors are for you to eventually get off.

I don't know who thought of this system. That's just how it is.

Yes, I agree. The first half of the bus gets packed tighter than the Winnipeg Arena when they were losing the Jets. Especially at rush-hour stops. But when you are a foreigner, you hafta accept things you don't necessarily understand. Besides, we have some illogical ways of being in Canada. For example, we mix man-made snow with a sugary sott-drink, call it "Slurpee," and sell them to stay cool in summer. Like we don't have enough snow the rest of the year, we need to drink sweet flavored snow to remind us of what will come around again in a few short months.

Wait. You can't give him a 10\$R bill when the fare is 1.40\$R. He won't accept it because they don't carry a lot of change. If you don't buy bus tickets before, come with just a few bills or correct change because you can't get through to the back of the bus without paying for your ticket. That happened to me once. Luckily, a young woman who spoke English paid for me. Otherwise I would have been late for work because I would have had to get off the bus, go find change, and take another bus. You have the correct change here. The money here isn't different colors or sizes like in Canada so it's best to count it before you get on the bus. OK, let's go.

HOLD ON!

Unless you can find a seat, you need to hold on.

No, I don't know how fast he's going.

To be honest with you, I don't think it matters whether this speed is legal or not.

Think of the balancing act of steadying yourself as exercise, OK? You get a workout for your money.

I don't know how they can sleep with the bus thrashing around, either. But in general, Brazilians work longer hours than we do in Canada, so they must be pretty tired.

Look, if you wanted comfort, you really should have rented a car. I'm trying to help you out here. Keep an open mind. Life is an adventure. 
(Five stops later)

I hate to tell you this, but it's a pretty busy time of day. You're gonna hafta surrender some of your personal space.

No need to clutch your wallet with the fear of God. It makes you look like you have a wallet worth stealing. You shouldn't be carrying around a lot of money anyway.

Please try to relax a little. He's not "breathing on you" on purpose. It's just really crowded in here. Look, I don't know what they are saying, either. I can catch some of the words but I think they are speaking a lot of slang and l'm learning correct Portuguese. They are talking about football (soccer) that's for certain. I know the names of the teams here because my boyfriend, his friends, and my male students are pretty crazy about the sport.

Are you watching for your stop? Look for buildings, places, or things you saw before. Try to get an idea of where you are, OK?

Yeah. You're right. You look like a tourist compared to everyone else. But what do you expect? You've got English on your shirt and you are the color of a Canadian winter. Listen, the second rule of being a foreigner is "Be proud of who you are and where you are from."

Don't let go of the hand rail. Stop showing off. You're gonna knock someone else over.

Aw man. You missed your stop.

Let's move towards the door. Say "Com lee-sen-sa." It's kinda like "Coming through" but in Portuguese.

Now push the button near the door. See the light up there? The driver knows you want to get off at the next stop.

\section{SCREEEEEEEEEEECH.}

Don't just stand there. Get off! The bus doesn't wait for day dreamers and ogling tourists.

Now, let's walk back to your stop.

So, Sandie and Yatta. I am feeling greatly discouraged but I want to write more than anything (yet another paradox: paralyzed by en-" thusiasm). I have also met few TESL "professionals" on the buses or in the streets but many are interested in teaching ESL to have fun in Brazil. This kind of company I avoid. I speak Portuguese with my new friends and Brazilian colleagues as much as possible now. It's not always correct but I can carry a conversation. I would appreciate a word of advice as a TESL theorist, professional, and writer. Maybe it's best to say that I am now less naive about the world. But what do I do with these new realities?

\section{A Gringa in the Borderlands}

A Gringo/a (foreigner) walks on the border between two worlds. Sometimes the border is a tightrope stretched taut, high up in the air, and we struggle to balance ourselves. These are lonely days. Other times the border is a highway we travel in an experience, an adventure we feel fortunate, even elated to be living. On those days I consider myself a kind of "excitement junkie." Or if I really want to flatter myself, I think of myself as the renegade among 
my childhood friends who now have professional jobs and secure lives in the country we grew up in. But depending on the situation that $I^{\prime} \mathrm{m}$ in, whom I am with, or if I've been there before, I am always trying to prevent myself from falling or crashing on either side of the border, for I cannot fully accept or give up either side.

Whether you are a Gringo running to a job, a person, an education, or a responsibility or a Gringo running away from a job, a person, an education, or responsibility, for any extended period of time, you run the risk of never really fitting into either the new country or the old one when you return home. I think that the only way to avoid this unpleasant (non)destination is to decide what in your life lies on which side of the border. What will you preserve and protect in you from the mother culture and what will you accept in the new culture? Some people will tell you that time will sort everything out. But frankly, I think you need to set some priorities before you lose yourself or your family at the border crossing.

I think these priorities are important because, although we cannot change the color of our skin or others' reactions to it, I think that we naturally seek to belong in the new territory. The taste buds find delight in new foods that fill our bellies. The eyes discover new sights through the glass windows of buses, trains, taxicabs, and cars or witness different worlds by wandering through city districts with conspicuous fold-out maps. The ears become attuned to the sounds of music, traffic, bells, birds, or silence, while the nose learns the local breads, fruits, or the current standard of waste and/or environmental management. The body can be clothed in different fashions from boutiques with names you initially can't pronounce (but who accept credit willingly). We can challenge our legs and feet to walk over cobblestones in heels, glide over icy patches, earn a black sock of dirt inside our sandals in polluted cities, puff up and swell in the heat, endure painful blisters, stand in line for hours, stride across manicured greens, or tiptoe over white-hot sand. And if you travel to a country where the aesthetic services are cheaper than borscht at the current exchange rate or the salary you earn, you can be massaged, soaked, filed, polished, painted, exfoliated, waxed, shaved: in short, externally beautified and relaxed in the local style. Depending on the country, we have the option to pay someone to do the cleaning, buy a machine, or simply accustom ourselves to washing our clothes in a sink and waiting two days for them to dry. But whether it is for an extended vacation, a job, or a lifetime in a foreign country, we explore. We learn. We find serenity in new routines. And we eventually adapt. But it is this very borderland route we take as we adapt that I am interested in poking fun at, celebrating, and mourning.

In the process of adapting, one of the most difficult lessons is teaching our tongue to dance to a different song. It takes time to learn the new moves or even open our mouths and get out on the dance floor. The index finger will 
only get you so far. The middle finger will get you nowhere. Pointing is embarrassing, annoying, and frustrating (or even insulting in some countries). So, sooner than later, we need these new dance steps to order a meal, call a cab, buy a train ticket, request a smaller size (or larger size if the food is good) or a different color in the boutiques, ask directions, request a service, and most important, to stay safe.

Language-learning in a foreign language context is a unique, humbling, trying, and rewarding experience. I wish it on everyone. For we do not just learn words and sounds, but rather, we learn another way of looking at and being in the world. I am of the firm belief that speakers of any given language, be it Portuguese, English, Russian, Japanese, Arabic, or Swahili, "live the language," meaning that language exists for the purpose of creating oneself over a lifetime in one's culture. However, with this in mind, imagine the task of a foreigner or immigrant in a country with a different language. By learning another language in context, the foreigner challenges what he or she takes for granted in and through their first language. For the foreigner learns another point of view, another frame of reference in the second language. Thus Gringos need to fashion a new self, one that walks, dances, drives, or balances through borderlands of the old and new cultures.

The process of acculturation is long and emotional. And we are lucky when we can find the support of others both in familiar and unfamiliar cultures to teach us a few dance moves, pick us up when we are down, or enjoy the ride with us. I hope these stories will enlighten or amuse readers who are living, have lived, or always wanted to live in another country as a Gringo/a.

So, Sandie and Yatta, by now you're probably wondering if I'll go ahead and do my research project. Of course, I will. Because there are a lot of interesting questions that will come of asking English students what the pictures in their texts teach them, new questions about my topic of interest and our research practice that were not raised in my first three months here. And as you can see, my fingerprints are all over this project. So let's see what the research brings. Us.

\section{Cosette}

\section{The Author}

Cosette Taylor is a Master of Education student in the field of TESL. She is currently exploring the sociocultural meaning that students infer from pictures in English-language texts produced in English-speaking countries for the Brazilian EFL market. She is also studying the effects of English-language instruction in a community-based development organization for impoverished youth in São Paulo, Brazil. Cosette has taught English in Austria, Poland, Canada, and Brazil. 